\title{
2D-3D Ultrasound in the Diagnosis of Uterine Malformations
}

\author{
G Canzone, M Parlato, L Triolo
}

\author{
A.S.L. 6 Palermo,U.O.C. Ostetricia e Ginecologia, P.O. S.Cimino Termini Im Casa di Cure Triolo Zancla, Palermo \\ Correspondence: G Canzone, U.O. di Ostetricia e Ginecologia, P.O.S. Cimino, Termini Imerese-PA, Italy. \\ e-mail: gicanzone@tiscali.it
}

\section{INTRODUCTION}

Uterine malformations form a non-homogenous group of pathologies with a variable impact on reproduction, often not strictly related to the apparent seriousness of pathology. It concerns about $1-5 \%$ of women.

Among the many tecniques, invasive and not, useful to diagnosis, many authors believe that laparoscopy associated with hysteroscopy allows diagnosis in all cases. Many references confirm this opinion: hysteroscopy and laparoscopy are used in the classification of uterine anomalies. ${ }^{1,2}$

Magnetic resonance imaging, safe and little invasive, gives a diagnostic accuracy close to $100 \%$. From 1997 to nowadays magnetic resonance has demonstrated its role in the imaging of female pelvis. Pellerito et al using magnetic resonance correctly diagnosed 24 of 24 anomalies (100\% accuracy), compared to 11 of 12 anomalies (92\%) using endovaginal sonography. Magnetic resonance imaging demonstrated $100 \%$ sensitivity and specificity compared to $67 \%$ sensitivity and $100 \%$ specificity of transvaginal sonography for unicornuate or bicornuate uteri (anomalies requiring surgery). For non-surgical uterine anomalies, both techniques had $100 \%$ sensitivity and specificity.

Pellerito et al also noted that magnetic resonance imaging had the further advantage of detecting other incidental abnormalities, including a dermoid and submucosal leiomyoma, not found on transvaginal ultrasound (indeterminate and nonvisualized). ${ }^{3-5}$

A review by Troiano et $a l^{16}$ confirms that the need for diagnostical surgical intervention has largely been eclipsed with the advent of magnetic resonance imaging, which has become the imaging modality of choice for characterization of congenital mullerian anomalies. ${ }^{17}$

Ultrasound imaging, in its various techniques available, gives $92 \%$ or more of diagnostic accuracy, with some advantages, like lower costs, availability of equipments, non invasivity, repeatability, use at an early stage of pregnancy.

The traditional 2D ultrasound gives a good visualization of the uterine outline and a good endometrial image as well. The main difficulty is obtaining especially in "non-ideal" patients, all the correct sections, which is absolutely necessary to identify malformations, especially the coronal section. These limits of the bidimensional scanning were noted from 1987 in a study by Nicolini et $a l .^{7}$ The authors founds that transabdominal 2D sonography failed to visualize the uterine cavity adequately in as many as $35 \%$ of patients although it adequately imaged the uterine fundus in $90 \%$ of patients.

For reasons not been elucidated, patients with uterine malformations often have preterm birth. Transvaginal ultrasound examination is an accurate test for the prediction of preterm birth. A study by Airoldi et al, ${ }^{15}$ examined specifically preterm birth in this population, evaluating 64 pregnancies : there were 28 with a bicornuate uterus, 13 with a septate uterus, 11 with a uterine didelphys, and 12 with a unicornuate uterus. They were followed prospectively. In women with uterine anomalies, if transvaginal scan shows a short cervical length, exists a 13fold risk for preterm birth. Unicornuate uterus had the highest rate of cervical shortening and preterm delivery (level of Evidence: II-2) (Figs 1 to 3).

Sonohysterography provides further information on the endometrial cavity. In a study by Sergeant et $a l^{8}{ }^{8} 14$ patients with a history of repeated spontaneous abortion or infertility, after the hysterosalpingography were examined by hysterosonography. The uterine septum were diagnosed by hysterosonography in all 14 patients $(100 \%)$. A recent study that evaluates the role of saline infusion sonohysterography in the investigation of uterine abnormalities and malformations in

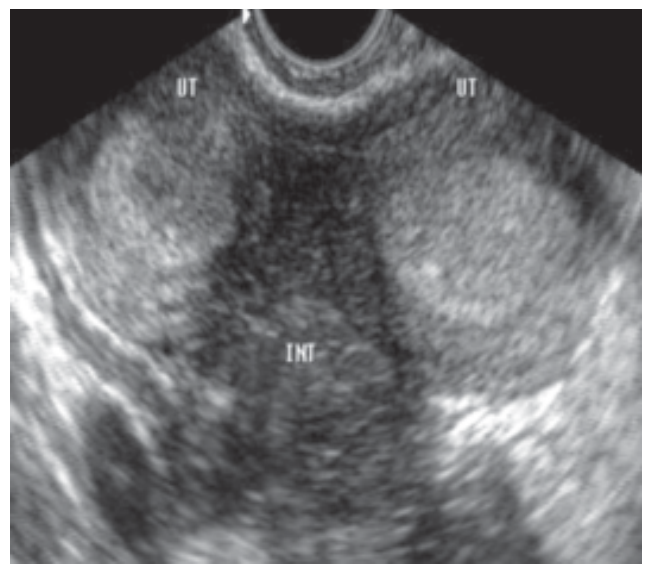

Fig. 1: Uterus didelphys, 2D scan 
1009 patients, ${ }^{11}$ demonstrates $20 \%$ of uterine anomalies in patients referred for infertility. The technique, used in an outpatient setting, appeared safe, well tolerated, and should be considered routinely in infertile patients.

2D transvaginal contrast sonography and 3D transvaginal ultrasound in the diagnosis of congenital uterine anomalies has provided sensitivity rates of up to $100 \%$ about uterine anomalies. ${ }^{14}$

Color Doppler adds important information on the vascularization of the malformed uterus, especially on the septum. The role of vascularization in the reproductive future of women with uterine malformation was suggested by some studies. ${ }^{12,21}$

Only 12 studies are reported in PubMed related to keywords "uterine malformations and 3D ultrasound" and similar, and there aren't metanalises of controlled trials that evaluate 2D ultrasound versus 3D in the diagnosis of the uterine malformations.

From 1995, some studies have found that three dimensional sonography is highly sensitive (up to $100 \%$ ) and specific (up to $100 \%$ ) in helping to diagnose major müllerian anomalies (Jurkovic). Studies also have found 2D transvaginal sonography to be a highly effective means of diagnosis, with $75-100 \%$ sensitivity and up to $95 \%$ specificity. Positive predictive value was higher with 3D scanning compared to 2D scanning (100\% vs 50\%, respectively). Three dimensional ultrasound agreed with hysterosalpingography in all major uterine anomalies. The ability to visualize both the uterine cavity and the myometrium on a 3D scan facilitates the diagnosis of uterine anomalies and enables easy differential diagnosis between subseptate and unicornuate uterus. ${ }^{5}$

In a study by Raga et al, 3D US detected 12 of 12 congenital uterine anomalies. The anomalies were correctly classified (according to AFS class) in 11 of 12 patients. A leiomyoma caused the misdiagnosis of a bicornuate uterus as septate uterus. ${ }^{6}$

In a study by Lev-Toaff et $a l,{ }^{9} 20$ women were studied by three-dimensional sonohysterography, 13 also by twodimensional sonohysterography, and 12 had X-ray hysterosalpingography. 3D sonohysterography gives additional information in the vast majority of women, compared with standard accepted techniques. The coronal plane was most useful for displaying the uterine cavity.

Many authors report that 3D ultrasound offers the three dimensional image of the uterus, with striking images of the conformation of the cavity and outline of the uterus, The most important aspect is the perfect visualization of the coronal scanning from the bottom to the cervix, which generally gives more information and which is, on the contrary, very difficult to visualize in 2D ultrasound. The outline of the uterus is perfectly visible as it would be with laparoscopy. In the future, according to a study by Alborzi et al, ${ }^{10}$ the 3D ultrasound might replace

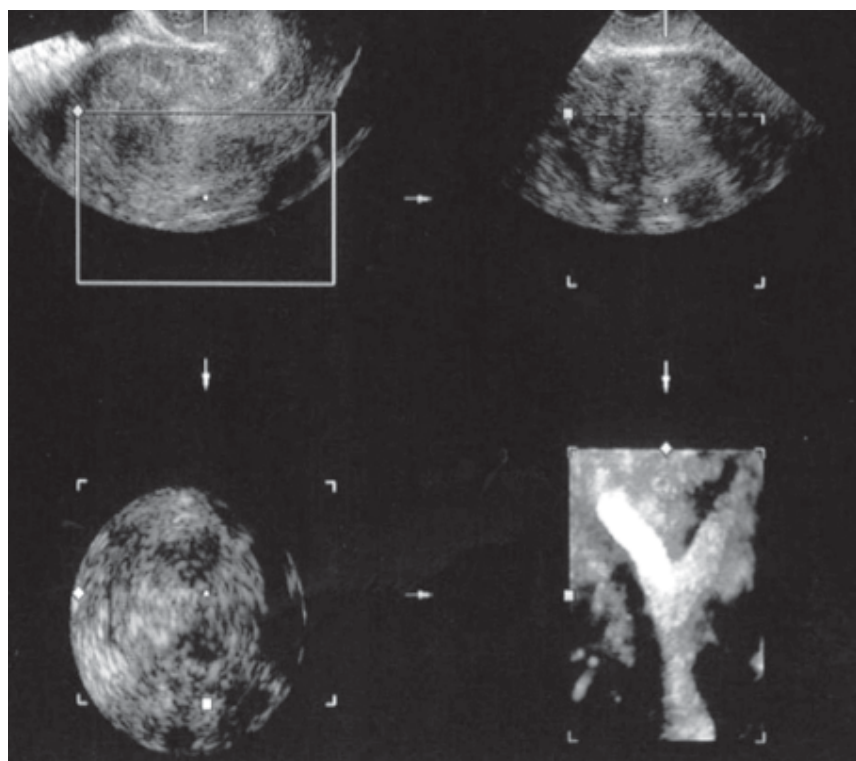

Fig. 2: Bicornuate uterus, 2D versus 3D imaging

laparoscopy in the diagnosis of the uterine malformations, especially in case of septate uterus. ${ }^{20}$

A study by Kupesic and Kuriak et $a l,{ }^{13}$ reports that threedimensional ultrasound can be a screening method for detection of uterine abnormalities in a population of infertile patients. In $23,2 \%$ of 3850 infertile patients, 3D US detected major uterine anomalies. The prevalence of septate uterus, the most common uterine abnormality, was $17.9 \%$.

3D ultrasound proves to be very useful for the differentiation between subseptate uterus and bicornuate and is absolutely necessary for the diagnosis of a malformation of less importance but difficult identification: arcuate uterus, which is not always visible with $2 \mathrm{D}$ ultrasound. 3D ultrasound shows with great precision the border between endometrium and myometrium and the slight convexity of the uterine bottom.

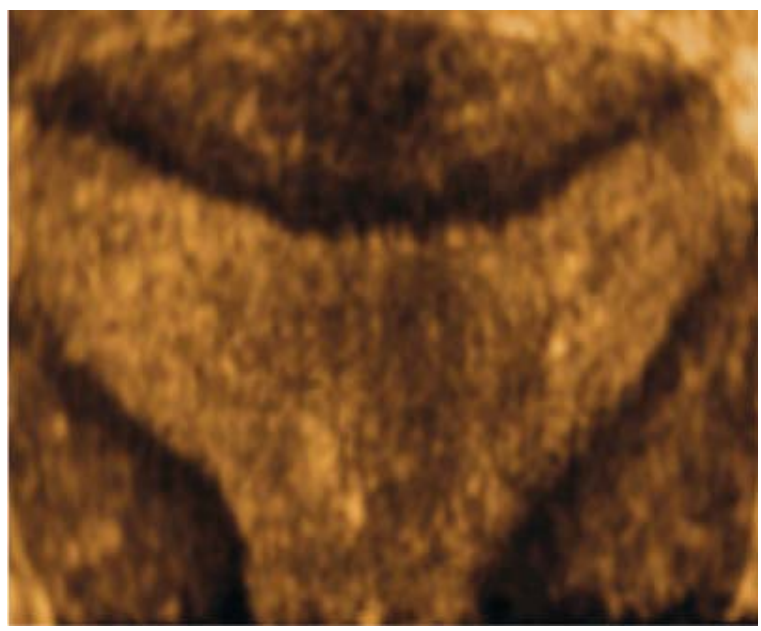

Fig. 3: Arcuate uterus, 3D imaging 
The 3D ultrasound is a reproducible method for the diagnosis of congenital uterine anomalies. Salim et al in a study performed to examine the reproducibility of the diagnosis of uterine malformations by $3 \mathrm{D}$ ultrasound ${ }^{22}$ demonstrate in 83 examined volumes only a single case of anomaly described as arcuate uterus by one ecographer and as subseptate by another.

A limit of 3D ultrasound may be the long time necessary to acquire and elaborate scan. An interesting study by Benacerraf et $a l^{18}$ determines whether 3-dimensional ultrasound is a rapid, efficient way to do a gynecologic scan. The authors scanned 35 cases with 2D and 3D sonography. The accuracy was similar. The average time needed for the standard 2D scan was 2,6 minutes. The time needed for 3D scan was 1,07 minutes (volume acquisition) and 1,19 minutes (offline elaboration): 2,26 minutes for the entire 3D examination. This study shows that 2D and 3D ultrasound need about the same time to scan uterus.

In early pregnancy, the three-dimensional ultrasound does not generally provide further information on the malformation and classic 2D scan is probably sufficient.

In our experience, the 3D ultrasound represents a second step in the diagnostic process on those patients where a 2D makes us suspect a uterine malformation. It is useful not so much to confirm the existence of a pathology, but mainly to allow us a more precise definition of the uterus morphology and to express a reproductive prognosis as much realistic as possible. $^{19}$

\section{REFERENCES}

1. AFS. The American Fertility Society classifications of adnexal adhesions, distal tubal occlusion, tubal occlusion secondary to tubal ligation, tubal pregnancies, mullerian anomalies and intrauterine adhesions. Fertil Steril 1988;49(6):944-55.

2. Golan A, Langer R, Bukovsky I, Caspi E. Congenital anomalies of the mullerian system. Fertil Steril 1989;51(5):747-55.

3. Pellerito JS, McCarthy SM, Doyle MB, et al. Diagnosis of uterine anomalies: relative accuracy of MR imaging, endovaginal sonography, and hysterosalpingography. Radiology 1992; 183(3):795-800.

4. Haimovici JBA, Tempany CMC. MR of the female pelvis: Benign disease. Applied Radiology [serial online] 1997;7-22.

5. Jurkovic D, Geipel A, Gruboeck K, et al. Three-dimensional ultrasound for the assessment of uterine anatomy and detection of congenital anomalies: a comparison with hysterosalpingography and two-dimensional sonography. Ultrasound Obstet Gynecol 1995;5(4):233-7.

6. Raga F, Bonilla-Musoles F, Blanes J, Osborne NG. Congenital Mullerian anomalies: diagnostic accuracy of three-dimensional ultrasound. Fertil Steril 1996;65(3):523-8.

7. Nicolini U, Bellotti M, Bonazzi B, et al. Can ultrasound be used to screen uterine malformations? Fertil Steril 1987;47(1):8993.
8. Salle B, Sergeant P, Gaucherand P, Guimont I, de Saint Hilaire P, Rudigoz RC. Transvaginal hysterosonographic evaluation of septate uteri: a preliminary report. Hum Reprod 1996;11(5): 1004-7.

9. Lev-Toaff AS, Pinheiro LW, Bega G, Kurtz AB, Goldberg BB. Three-dimensional multiplanar sonohysterography: comparison with conventional two-dimensional sonohysterography and X-ray hysterosalpingography. J Ultrasound Med 2001;20(4): 295-306.

10. Alborzi S, Parsanezhad ME, Mahmoodian N, Alborzi S, Alborzi M. Sonohysterography versus transvaginal sonography for screening of patients with abnormal uterine bleeding. J Gynaecol Obstet 2007;96(1):20-3. Epub 2006 Dec 21.

11. Tur-Kaspa I, Gal M, Hartman M, Hartman J, Hartman A. A prospective evaluation of uterine abnormalities by saline infusion sonohysterography in 1,009 women with infertility or abnormal uterine bleeding. Fertil Steril 2006;86(6):1731-5. Epub 2006 Sep 27.

12. Canzone G,Parlato M. Classificazione ecografica delle malformazioni uterine e prognosi riproduttiva. Atti VI Corso di Aggiornamento in Medicina Embrio-fetale e Perinatale; Villasimius (CA) 18-21/5/ 2006;389-93.

13. Kupesic S, Kurjak A, Skenderovic S, Bjelos D. Screening for uterine abnormalities by three-dimensional ultrasound improves perinatal outcome. J Perinat Med 2002;30(1):9-17.

14. La Torre R, Prosperi Porta R, Franco C, Sansone M, Mazzocco M, Pergolini I, et al. Three-dimensional sonography and hysterosalpingosonography in the diagnosis of uterine anomalies. Clin Exp Obstet Gynecol 2003;30(4):190-2.

15. Airoldi J, Berghella V, Sehdev H, Jack Ludmir. Transvaginal Ultrasonography of the cevix to predict preterm birth in women with uterine anomalies.Obstetrics \& Gynecology 2005;106:5536.

16. Troiano RN, McCarthy SM. Müllerian duct anomalies: imaging and clinical issues. Radiology 2004;233(1):19-34.

17. Troiano RN.Magnetic resonance imaging of mullerian duct anomalies of the uterus.Top Magn Res Im 2003;14:(4).267.

18. Benacerraf BR, Shipp TD, Bromley B. Improving the efficiency of gynecologic sonography with 3-dimensional volumes: a pilot study. J Ultrasound Med 2006;25(6);813.

19. Canzone G, Parlato M. Ecografia delle malformazioni uterine. In Manuale di Ecografia Ginecologica, Editeam, 2006.

20. Alborzi S,Dehbashi S, Parsanezhad ME. Differential diagnosis of septate and bicornuate uterus by sonohysterography eliminates the need for laparoscopy. Fertil Steril 2002;78(1):176-8.

21. Woelfer B, Salim R, Banerjee S, Elson J, Regan L, Jurkovic D. Reproductive outcomes in women with congenital uterine anomalies detected by three-dimensional ultrasound screening. Obstet Gynecol 2001;98:1099-1103.

22. Salim R,Woelfer B, Backos M, Regan L, Jurkovic D. Reproducibility of three-dimensional ultrasound diagnosis of congenital uterine anomalies. Ultrasound Obstet Gynecol 2003;21(6).578-82. 